Afr. J. Trad. CAM (2007) 4 (2): 240 - 244

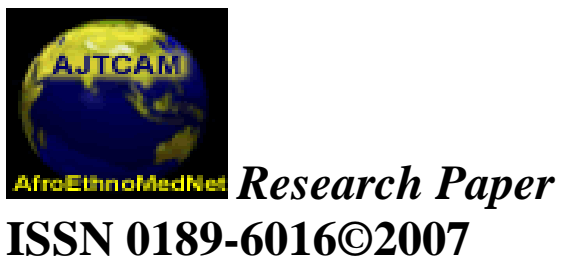
Afr. J. Traditional, Complementary and Alternative Medicines www.africanethnomedicines.net

\title{
ANALGESIC AND ANTI-INFLAMMATORY PROPERTIES OF AQUEOUS EXTRACT FROM LEAVES OF SOLANUM TORVUM (SOLANACEAE)
}

\author{
E. J. Ndebia ${ }^{1}$, R. Kamgang ${ }^{1}$ and B. N. Nkeh-ChungagAnye ${ }^{{ }^{*}}$ \\ ${ }^{1}$ Department of Biology and Animal Physiology, Faculty of Science, \\ P. O. Box 812, University of Yaounde I, Yaoundé - Cameroon. \\ *Email: bnkeh@uycdc.uninet.cm, Fax: (237)222 1873.
}

\begin{abstract}
Solanum torvum is used in Cameroonian traditional medicine for the management of pain and inflammation. The present work assesses the pain-killing and anti-inflammatory properties of the aqueous extracts of Solanum torvum leaves. Acetic acid- and pressure- induced pains were reduced by this extract while carrageenan-induced inflammation was inhibited at various doses of the extract. The extract therefore has both analgesic and anti-inflammatory properties.
\end{abstract}

Key words: Analgesic, inflammation, Solanum torvum, writhing, Analgesy Meter.

\section{Introduction}

Solanum torvum (Solanaceae) also known as 'top na aka' in the Batoufam language, is a plant used in Cameroonian folk medicine for the treatment of fever, wounds, and tooth decay. This plant is also used for its haemostatic properties (Henty, 1973). Recent investigations demonstrated that Solanum Torvum (S. torvum) has antimicrobial activity (Chah et al., 2000). Importantly, isoflavonoids isolated from this plant showed significant antiviral properties (Arthan et al., 2002). Since no literature is currently available to substantiate the analgesic and anti-inflammatory properties of $S$. torvum, the present study was designed to provide scientific evidence of the claimed ethnopharmacological properties by investigating the analgesic and anti-inflammatory properties of this plant.

\section{Experimental Plant material}

The fresh leaves of S. torvum were harvested in the month of September 2003, in the Yaoundé area, Cameroon and identified at the National Herbarium, Yaoundé, where a voucher specimen HNC No 21103 was deposited. Harvested leaves were air-dried away from direct sunshine after which they were ground to powder in a food processor. $100 \mathrm{~g}$ of ground leaves powder were macerated for $2 \mathrm{~h}$ in $500 \mathrm{ml}$ distilled water at $90^{\circ} \mathrm{C}$. After filtration, the aqueous filtrate was concentrated by evaporation at $40^{\circ} \mathrm{C}$ and yielded $12.8 \mathrm{~g}$ of dry powder. Preliminary phytochemical screening of the aqueous extract of $S$. torvum revealed the presence of sterol, triterpenes, sugars, alkaloids and phenols.

\section{Animals}

Wistar rats (weighing 160-220 g) and Swiss mice (weighing 20-30 g) of both sexes were bred in our animal house at room temperature and had access to food and water, ad libitum. Prior to treatment, the experimental animals were fasted overnight but allowed access to drinking water. Ethical approval for this study was obtained from the Research Board of the University of Yaoundé I. 


\section{Drugs}

Ndebia et al., Afr. J. Trad. CAM (2007) 4 (2): 240 - 244

Aspirin (Aspegic ${ }^{\circledR}$, Sanofi-Synthelabo France), Indomethacine (Indocid ${ }^{\circledR}$, Laboratoire Merck Sharp et Dohme France), Morphine (Sigma-Aldrich-Quiinina S.A. Madrid-Spain), Tramadol (Laboratoire Pharmascience, France, Couveboie) and plant extract were dissolved in distilled water, Carrageenan (Sigma Chemical Co, St Louis, USA) in physiological saline.

\section{Nociceptive activities}

The analgesic activity of $S$. torvum was measured against chemical and mechanical stimuli.

\section{Acetic acid-induced abdominal writhing test}

30 swiss mice were divided into six groups of five animals each. Each group of animals was treated orally with one of the following: $\mathrm{NaCl} 9^{0} \%$, aspirin $(100 \mathrm{mg} / \mathrm{kg})$, tramadol $(25 \mathrm{mg} / \mathrm{kg})$, morphine $(1.5 \mathrm{mg} / \mathrm{kg}), S$. torvum $(300 \mathrm{mg} / \mathrm{kg}$ ) and $(600 \mathrm{mg} / \mathrm{kg})$ respectively. One hour after administration of the test drugs, animals were injected intra-peritoneally with $1 \%$ acetic acid $(1 \mathrm{ml} / 100 \mathrm{~g}$ body weight). The number of writhing responses such as contortions and stretching were recorded for 30 minutes. The results were evaluated by calculating the mean number of contortions per treated group and results compared to results obtained from control animals. Percentage pain inhibition was calculated as follows.

$$
\begin{aligned}
& \text { Pain inhibition }(\%)=\frac{\bar{N} c-\bar{N} t}{\bar{N} c} \times 100 \\
& \overline{N c}: \text { mean number of contortions of the control group } \\
& \overline{N t}: \text { mean number of contortions per treated group }
\end{aligned}
$$

\section{Pressure test}

In these experiments, the drugs cited above were tested at the same dose levels in rats using an Ugo Basile Analgesy Meter ( $\mathrm{N}^{\circ}$ 7200). A constantly increasing force was applied to the left hind paw of experimental animals by the Analgesy Meter plunger. Rats were restrained in the upright position while their left hind paws were placed between the plinth and the plunger. Pain was determined by the physical struggles of the animal to set itself free. The weight causing pain before treatment and then 1,2 and $3 \mathrm{~h}$ after treatment of animals with the various test drugs was determined. Pain inhibition rates were calculated as follows.

$$
\text { Pain inhibition }(\%)=\frac{\overline{F t}-\overline{F O}}{\overline{F O}} \times 100
$$

$\overline{F O}$ : force at which the animal struggles to free its paw before administration of drugs.

$\overline{F t}$ : force at which the animal struggles to free its paw after administration of drugs.

\section{Carrageenan-induced paw edema}

Oedema was induced on the right hind paw of rats by a sub-plantar injection of $0.05 \mathrm{ml}$ of a solution of $1 \%$ sterile carrageenan in saline(Lanhers et al., 1991). The plant extract (300 and $600 \mathrm{mg} / \mathrm{kg}$ ) and Indomethacine $(10 \mathrm{mg} / \mathrm{kg})$ were administered orally 30 minutes before carrageenan injection while control animals received the vehicle only. The volume of the injected paw was measured before and 1, 2, 3, $4 \mathrm{~h}$ after induction of inflammation using a Plethysmometer (Ugo Basile $\mathrm{N}^{\circ} 7140$ ). Inflammation was expressed as an increase in paw volume due to carrageenan injection. Oedema $(\Delta \mathrm{V})$ and inhibition rate $(\mathrm{I} \%)$ were calculated as follows.

$$
\begin{aligned}
& \Delta \mathrm{V}=\overline{v t}-\overline{v o} \\
& I \%=\frac{(\overline{v t}-\overline{v o}) C-(\overline{v t}-\overline{v o}) E}{(\overline{v t}-\overline{v o}) C} \times 100
\end{aligned}
$$

$\overline{v t}$ : right hind paw volume at time t. C: control group, E: experimental group

$\overline{v O}$ : right hind paw volume before sub-plantar injection of carrageenan 
Ndebia et al., Afr. J. Trad. CAM (2007) 4 (2): 240 - 244

\section{Statistical analysis}

One way ANOVA followed by Dunnets multiple comparison tests were performed. The differences between groups were considered significant when $\mathrm{P}<0.05$. The statistical package used for these analyses was Instat. Results are expressed as mean \pm SEM

\section{Results}

\section{Antinociceptive effects \\ Acetic acid-induced abdominal writhing test}

The results presented in Table 1 show that $S$. torvum extract at doses of 300 and $600 \mathrm{mg} / \mathrm{kg}$ po decreased the number of writhes by $23 \%$ and $26 \%(\mathrm{p}<0.05)$ respectively. The reference drugs (Morphine, Tramadol and Aspirin) induced significant $(\mathrm{P}<0.01)$ reduction of the noted parameters by $61 \%, 23 \%$ and $48 \%$ respectively. Pain inhibition by $300 \mathrm{mg} / \mathrm{kg}$ of the extract was similar to the results obtained with tramadol. Although two doses were used, the higher dose $(600 \mathrm{mg} / \mathrm{kg})$, did not elicit a greater protection from acetic acid induced abdominal writhing as would have been expected.

Table 1: Effect of the aqueous leave extracts of $S$. torvum on acetic acid-induced pain.

\begin{tabular}{lccc}
\hline Group & Dose $(\mathbf{m g} / \mathbf{k g})$ & Contraction \pm SEM & Pain inhibition (\%) \\
\hline Control & - & $148 \pm 14$ & 48 \\
Aspirin & 100 & $77 \pm 8^{* *}$ & 23 \\
Tramadol & 25 & $113 \pm 10^{*}$ & 61 \\
Morphine & 1.5 & $58 \pm 8^{* *}$ & 23 \\
S. torvum & 300 & $114 \pm 9^{*}$ & 26 \\
S. torvum & 600 & $110 \pm 13^{*}$ & 23 \\
\hline
\end{tabular}

Test groups were compared with the control group and significant differences in response were noted. $* \mathrm{P}<0.05$, $* * \mathrm{P}<0.01 . \mathrm{n}=5$

Table 2: Effect of the aqueous leave extracts of $S$. torvum on pressure-induced pain. Measurements (in gf (gram force)) were done before the administration of the various drugs and at various time intervals after drug administration. Every animal served as its own control.

\begin{tabular}{|c|c|c|c|c|c|c|c|}
\hline \multirow[t]{2}{*}{ Group } & \multirow{2}{*}{$\begin{array}{c}\text { Dose } \\
\text { (mg/kg) }\end{array}$} & \multicolumn{2}{|c|}{$\begin{array}{l}\text { Before drug } \\
\text { administration }\end{array}$} & \multicolumn{4}{|c|}{ After drug administration (\% analgesia) } \\
\hline & & & & \multicolumn{2}{|c|}{ 1H } & $2 \mathbf{H}$ & \multirow[t]{2}{*}{$3 \mathbf{H}$} \\
\hline Control & - & $86 \pm 5$ & $80 \pm$ & & $92 \pm 5(7)$ & $86 \pm 5(0)$ & \\
\hline Aspirin & 100 & $89 \pm 4$ & $105 \pm 1$ & 18) & $102 \pm 6(15)$ & $95 \pm 4(7)$ & \\
\hline Tramadol & 25 & $78 \pm 5$ & $92 \pm$ & $18)^{*}$ & $130 \pm 4(67)^{* *}$ & $104 \pm 4(33)^{* *}$ & \\
\hline Morphine & 1.5 & $81 \pm 5$ & $107 \pm 7$ & $2)^{*}$ & $136 \pm 2(68)^{* *}$ & $106 \pm 10(31)^{*}$ & \\
\hline S. torvum & 300 & $80 \pm 2$ & $107 \pm$ & $34)^{*}$ & $113 \pm 7(41)^{*}$ & $105 \pm 6(32)^{*}$ & \\
\hline S. torvum & 600 & $82 \pm 4$ & $104 \pm 4$ & 7)* & $117 \pm 7(43)^{*}$ & $132 \pm 8(61)^{* *}$ & \\
\hline
\end{tabular}

Test groups were compared with the control group and significant differences in pain perception were noted. $\mathrm{P}<0.05 ; * * \mathrm{P}<0.01 . \mathrm{n}=5$ 
Ndebia et al., Afr. J. Trad. CAM (2007) 4 (2): 240 - 244

Table 3: Anti-inflammatory activity of aqueous extract of $S$. torvum in carrageenan-induced hind paw edema: expressed as a percentage of volume variation $(\Delta \mathrm{V}$ in $\mathrm{mL})$.

\begin{tabular}{cccccc}
\hline Group & $\begin{array}{c}\text { Dose } \\
\text { (mg/kg) }\end{array}$ & $\begin{array}{c}\mathbf{1 H} \\
\text { (\% inhibition) }\end{array}$ & $\begin{array}{c}\text { 2H } \\
\text { (\% inhibition) }\end{array}$ & $\begin{array}{c}\text { 3H } \\
\text { (\% inhibition) }\end{array}$ & $\begin{array}{c}\text { 4H } \\
\text { (\% inhibition) }\end{array}$ \\
\hline Control & - & $0.35 \pm 0.06$ & $0.52 \pm 0.08$ & $0.61 \pm 0.07$ & $0.55 \pm 0.05$ \\
Indomethacine & 10 & $0.20 \pm 0.01(43)$ & $0.20 \pm 0.02(62)^{* *}$ & $0.11 \pm 0.02(82)^{* *}$ & $0.08 \pm 0.04(85)^{* *}$ \\
S. torvum & 300 & $0.24 \pm 0.03(34)$ & $0.36 \pm 0.06(31)$ & $0.37 \pm 0.07(39)^{*}$ & $0.29 \pm 0.08(47)^{*}$ \\
S. torvum & 600 & $0.33 \pm 0.08(11)$ & $0.51 \pm 0.08(4)$ & $0.37 \pm 0.08(41)$ & $0.29 \pm 0.07(49)^{*}$ \\
\hline
\end{tabular}

Test groups were compared with the control group and significant difference were noted.

$* \mathrm{P}<0.05, * * \mathrm{P}<0.01 . \mathrm{n}=5$

\section{Pressure test}

Aspirin $(100 \mathrm{mg} / \mathrm{kg})$ did not show significant antinociceptive effect on mechanical pain. The analgesic effects of the aqueous extract of $S$. torvum leaves $(300$ and $600 \mathrm{mg} / \mathrm{kg}$ po) were significant one hour after drug administration, and the results were similar to those obtained with both morphine $(1.5 \mathrm{mg} / \mathrm{kg})$ and tramadol $(25$ $\mathrm{mg} / \mathrm{kg}$ ). Whereas the maximal pain blocking activity of tramadol, morphine and $300 \mathrm{mg} / \mathrm{kg} S$. torvum extract were observed two hours after drug administration, $600 \mathrm{mg} / \mathrm{kg}$ of $S$. torvum extract showed maximal activity $(\mathrm{p}<0.01)$ during the third hour after extract administration (Table 2). The analgesic effects of this extract dose was highest when the analgesic effects of all the other test drugs were already waning out.

\section{Carrageenan-induced paw edema}

Control animals showed progressively increasing paw volume in response to carrageenan injection during the experiment. $S$. torvum leaves aqueous extract significantly attenuated paw swelling $(\mathrm{P}<0.05) 2$ and 4 hours following oral administration (Table 3). The anti-inflammatory effect of the extracts were however not dose-dependent. Indomethacine had a greater inhibitory effect $(\mathrm{P}<0.01)$ on carrageenan-induced paw oedema compared to S. torvum.

\section{Discussion}

The present study, made use of two models for the investigation of the analgesic effect of S. torvum extract. Acetic acid induced writhing and pressure tests were selected to investigate peripheral and central antinociceptive effects of the plant extract. Carrageenan induced paw oedema in rat was selected to represent a model of acute inflammation.

The present results showed that the aqueous extract of $S$. torvum induced dose dependant analgesic effect against the writhing syndrome indicating its peripheral effect(Atta and Afolabi, 1997). In peripheral tissues, prostaglandins and kinines would seem to play an important role in the pain process (Hajare et al., 2000) and writhing induced by chemical substances injected intra-peritoneally is said to be the consequence of sensitisation of the chemosensitive nociceptors by prostaglandins (Maria et al., 1997). These results suggest that the pain killing effect of this plant may be by the prostaglandins synthesis inhibition. This test also confirms the peripheral action of Aspirin (Rang et al., 1995).

The pre-treatment of rats with $S$. torvum extract inhibited pain caused mechanically by a constantly increasing pressure on rat paw by the plunger and plinth of the Analgesy Meter. This system provides a model for the study of non inflammatory pain. The opioid-like analgesic drugs are more effective in inhibiting mechanically induced pain (Nkeh et al., 2002). In this model of pain, the involvement of endogenous substances such as prostaglandins may be minimized (Dongmo et al., 2001). The central protecting effect of S. torvum leaves extracts were comparable to tramadol and morphine test results. Tramadol is known to inhibit neuronal re-uptake of serotonin (Oliva et al., 2002) while morphine activity is mediated by $\mu$ opioid receptors (Raffa et al., 1993). Aspirin did not show analgesic effect on this model of pain, thus confirming the previous 
Ndebia et al., Afr. J. Trad. CAM (2007) 4 (2): 240 - 244

study in which Aspirin and Aspirin like drugs were ineffective against pain due to sensory nerve stimulation (Flower et al., 1985).

In the last part of the study, the carrageenan experimental model of inflammation was used to evaluate the anti-inflammatory effect of S. torvum. Some authors (Hwang et al., 1996; Lo et al., 1987), think that the initial phase of carrageenan paw oedema is mediated by histamine and serotonin, while the later phase is suspected to be due to arachidonate metabolites (prostaglandins, leukotrienes) producing oedema dependent on mobilisation of neutrophils. Although the cyclooxygenase and lipoxygenase pathways are both involved in the inflammatory process, inhibitors of cyclooxygenase are more effective in inhibiting carrageenan-induced inflammation than lipoxygenase inhibitors (Flower et al., 1985).

In our experiments, rats pre-treated with $S$. torvum extract showed a significant oedema inhibitory response $2 \mathrm{~h}$ following carrageenan injection. This result suggests that $S$. torvum extract may act by suppressing the later phase of the inflammatory process by the inhibition cyclooxygenase, the enzyme involved in the formation of prostaglandins.

The presented data therefore, indicate that the oral administration of Solanum torvum extract showed analgesic and anti-inflammatory activities. These properties confirm its use in folk medicine.

\section{References}

1. Henty, E.E. (1973). Weeds of New Guinea and their control. Department of Forests, Division of Botany. Botany Bulletin. No. 7. Lae, Papua New Guinea, PP 149-151.

2. Chah, K.F., Muko, K.N. and Oboegbulem, S.I. (2000). Antimicrobial activity of methanolic extract of Solanum torvum fruit. Fitoterapia, 71: 187-189.

3. Arthan, D., Svasti, J., Kittakoop, P., Pittayakhachonwut, D., Tanticharoen, M. and Thebtaranonth, J. (2002). Antiviral isoflavonoid sulfate and steroidal glycosides from the fruits of Solanum torvum (Solenaceae). Photochemistry, 39: 459-463.

4. Lanhers, M.C., Fleurentin, J., Dorfman, P., Motrier, F. and Pelt, J.M. ( 1991). Analgesic, antipyretic and antiinflammatory properteis of Euphorbia hirta. Planta Medica, 57:225-231.

5. Atta, A.H. and Alkofahi, A. (1997). Anti-nocive and anti-inflammatory effects of some Jordanian medicinal plant extracts. Journal of Ethnopharmacology, 60: 117-124.

6. Hajare, S.W., Suresh, C., Tandan, S.K., Sarma, J., Lal, J. and Telang, A.G. (2000). Analgesic and antipyretic activities of Dalbergia sissoo leaves. Indian Journal of Pharmacology, 32: 357-360

7. Maria Elena, N.G., José Arthur Da, S.E., Souccar, C. and Antonio, J.L. (1997). Analgesic and Anti-inflammatory Activities of the Aqueous Extract of Plantango Major L. International Journal of Pharmacognosy, 35: 99-104.

8. Rang, H.P., Dale, M.M. and Ritter, J..M. (1995). Pharmacology, Churchill. Livingstone: London.

9. Nkeh, C-A.B., Njamen, D., Wandji, J., Fomum, Z., Dongmo, A., Nguelefack, T.B., Wansi, B. and Kamanyi, A. (2002). Anti inflammatory and analgesic effect of Drypermolundein A, a sesquiterpene lactone from Drypetes molunduana. Pharmaceutical Biology, 4: 26-30.

10. Dongmo, A.B., Kamanyi, A., Anchang, M.S., Nkeh, C-A.B., Njamen, D., Nguelefack, T.B., Nole, T. and Wagner, H. (2001). Anti-inflammatory and analgesic properties of the stem bark extract of Erythrophleum suaveolens (Caesalpiniaceae), Guillemin $\alpha$ Perrottet. Journal of Ethnopharmacology, 7: 137-141.

11. Oliva, P., Aurilio, C., Massino, F., Grella, A., Maione, S., Grella, E., Scafuro, M., Rossi, F. and Berrino, L. (2002). The antinociceptive effect of tramadol in the formalin test is mediated by the serotonergic component. European Journal of Pharmacology, 445: 179-185.

12. Raffa, R.B., Friderichs. E., Reimann, W., Shank, R.P., Cood, E.E., Vaught, J.L., Jacob, H.I. and Selva, N. (1993). Complementery and synergistic antinociceptive interaction between the enantiomers of tramadol. Journal of Pharmacology and Experimental Therapeutics, 267: 331-340.

13. Flower, J.R., Moncada, S. and Vane, J.R. (1985). Analgésic, antipyretic and anti-inflammatory agents: Drugs employed in the treatment of gout. In : Goodman and Gilman's (Editors). The Pharmalogical Basic of Therapeutics $\left(6^{\text {th }}\right.$ eds. $)$, PP 682-728.

14. Hwang, S., Lam, M., Li, C. and Shen, T. (1996). Release of platelet activating factor and its involvement in the first phase of carrageenan rat foot edema. European Journal of Pharmacology, 120: 33-41.

15. Lo, T.N. and Sauf, S.S. (1987). Carrageenan stimulated release of arachidonic acid and of lactate dehydrogenase from rat pleural cells. Biochemical Pharmacology, 36: 2405-2513. 